\begin{tabular}{|c|c|c|c|c|c|c|}
\hline \multirow[b]{2}{*}{ IEXPAC item } & \multicolumn{6}{|c|}{ Percentage $(\%)$ who responded "mostly" + "always" } \\
\hline & $\mid \begin{array}{c}\text { All } \\
\text { patients }\end{array}$ & $\begin{array}{l}\text { Rheumati } \\
\text { c Disease }\end{array}$ & IBD & HIV & DM & $\mathbf{p}$ \\
\hline They respect my lifestyle & $81.5 \%$ & $76.5 \%$ & $75.1 \%$ & $89.6 \%$ & $81.9 \%$ & $<0.001$ \\
\hline They are coordinated to offer good health care to me & $69.3 \%$ & $60.6 \%$ & $69.1 \%$ & $76.8 \%$ & $73.3 \%$ & $<0.001$ \\
\hline They help me to get information from the Internet & $15.0 \%$ & $12.8 \%$ & $19.0 \%$ & $19.8 \%$ & $8.3 \%$ & $<0.001$ \\
\hline Now I can take care of me better & $81.0 \%$ & $74.3 \%$ & $79.3 \%$ & $89.7 \%$ & $78.3 \%$ & $<0.001$ \\
\hline They ask me and help me to follow my treatment plan & $79.8 \%$ & $73.5 \%$ & $77.8 \%$ & $87.6 \%$ & $78.2 \%$ & $<0.001$ \\
\hline We set goals for a healthy life and better control my & $70.1 \%$ & $63.4 \%$ & $62.6 \%$ & $74.7 \%$ & $76.1 \%$ & $<0.001$ \\
\hline $\begin{array}{l}\text { I can use Internet and my mobile phone to consult my } \\
\text { medical records }\end{array}$ & $7.2 \%$ & $7.3 \%$ & $5.5 \%$ & $8.6 \%$ & $7.1 \%$ & 0.529 \\
\hline They make sure that I take medication correctly & $76.0 \%$ & $72.4 \%$ & $73.7 \%$ & $83.5 \%$ & $72.9 \%$ & $<0.001$ \\
\hline They worry about my welfare & $84.3 \%$ & $79.1 \%$ & $80.4 \%$ & $91.5 \%$ & $83.8 \%$ & $<0.001$ \\
\hline I have been informed on the health and social & $41.3 \%$ & $33.8 \%$ & $32.3 \%$ & $52.6 \%$ & $42.3 \%$ & $<0.001$ \\
\hline They encourage me to talk to other patients & $14.9 \%$ & $10.3 \%$ & $15.7 \%$ & $20.4 \%$ & $12.0 \%$ & $<0.001$ \\
\hline $\begin{array}{l}\text { Respond to the following statement only if you } \\
\text { have been admitted to the hospital in the last } 3 \\
\text { years, } \\
\text { They care about me when I come home after being in } \\
\text { the hospital }\end{array}$ & $30.6 \%$ & $25.7 \%$ & $28.9 \%$ & $33.0 \%$ & $32.8 \%$ & 0.205 \\
\hline Global IEXPAC score, mean (SD) & $6.0(1.9)$ & $5.5(2.0)$ & $5.9(2.0$ & $6.6(1.7)$ & $5.9(1.9)$ & $<0.001$ \\
\hline
\end{tabular}

Conclusions: The IEXPAC questionnaire identified areas of improvement in chronic patients health care in Spain, especially those related with access to reliable information and services, interaction with other patients and continuity of health care after hospital discharge. Patients with HIV infection scored higher, maybe consequence of a more personalized care. In several items, patients with rheumatic diseases scored lower

Acknowledgements: Funded by Merck Sharp \& Dohme, Spain, with endorsement of 4 patients associations: CONARTRITIS (patients with rheumatid diseases), ACCU (patients with IBD), SEISIDA (HIV multidisciplinary group), FEDE (patients with DM)

Disclosure of Interest: None declared

DOI: 10.1136/annrheumdis-2018-eular.1588

\section{FRI0713-HPR THE PATIENTS' PERSPECTIVES TOWARDS THE PROVISION OF INFORMATION DURING TRANSITION TO A BIOSIMILAR}

J. Kreuk, A. Twisk, J. Meilink, R. Alblas, W. van der Weele, R.C. Hebing, J. Ruwaard, M. I'Ami, Z. Layegh, G. Wolbink. Amsterdam Rheumatology and Immunology Center Reade, Amsterdam, The Netherlands

Background: In July 2015, at the Amsterdam Rheumatology and Immunology Centre, location Reade, $93 \%$ of the patients with rheumatoid arthritis, treated with reference product infliximab switched to the biosimilar infliximab. This transition was needed to enable cost savings. Patients gained information via several ways, where the rheumatology nurses had a central role in informing the patients. Patients' perspectives are warranted to investigate the effect of the transition to the biosimilar.

Objectives: To investigate patients' perspectives towards the provided information regarding the switch to the biosimilar.

Methods: Consecutive patients treated with reference product infliximab were switched to the biosimilar in the period July 2015 to June 2016 at the Amsterdam Rheumatology and immunology Center, Reade. Patients were informed by a letter about the transition to the biosimilar and were subsequently contacted by a nurse or the pharmacist for additional questions and whether they agreed upon the switch. All patients who were switched from the reference product to the biosimilar were approached at the day care to fill in a questionnaire. In this qualitative questionnaire, patients were asked to evaluate the information provision process and how they gained information about the transition to the biosimilar initially. This was done by the nurses of the day care.

Results: All patients who switched to the biosimilar $(n=46)$ filled in the questionnaire, of which 15 patients scored the information provision as excellent (33\%), 25 patients as good (54\%), 4 patients as reasonable $(9 \%)$ and 2 patients found the information sufficient (4\%). Furthermore, the majority of patients was initially informed by nurses and rheumatologist prior to the letter that was send to all patients. In total, 12 patients were initially informed by rheumatology nurse (26\%), 12 patients by the rheumatologist (26\%). Four patients were informed via the letter that was send at first $(9 \%)$ and 3 patients gained the information about the transition otherwise $(7 \%)$. Fifteen patients gave more than one answer to the question by whom they were informed initially.

\section{A. Patient's perspective}

\section{B. Initially informed by:}
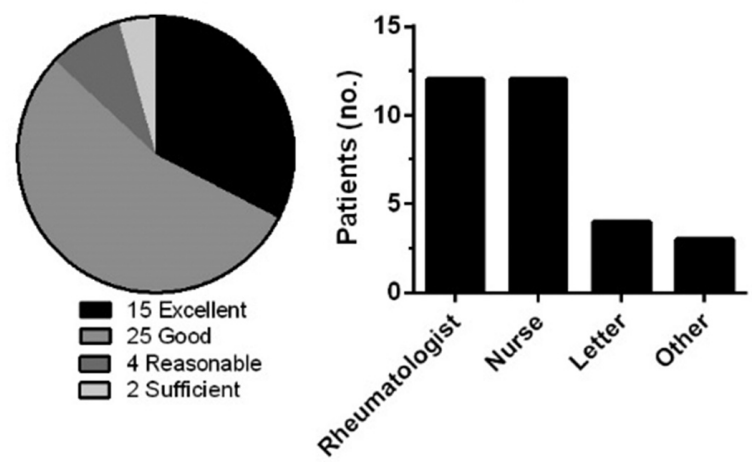

Conclusions: Patients were satisfied about the information provision process there were no patients who experienced the information provision insufficient Next to the rheumatologist, rheumatology nurses played an important role in informing the patients about the transition.

Disclosure of Interest: J. Kreuk: None declared, A. Twisk: None declared, J. Meilink: None declared, R. Alblas : None declared, W. van der Weele: None declared, R. Hebing : None declared, J.Ruwaard: None declared, M. I'Ami: None declared, Z. Layegh: None declared, G.Wolbink Grant/research support from: Pfizer, Speakers bureau: Abbvie, UCB, BMS,Pfizer DOI: 10.1136/annrheumdis-2018-eular.6884

\section{FRI0714-HPR THE PATIENT'S JOURNEY FROM ONSET OF BACK PAIN TO DIAGNOSIS OF AXIAL SPONDYLOARTHRITIS: RESULTS FROM A QUALITATIVE STUDY}

L. Passalent ${ }^{1,2,3}$, L. Soever ${ }^{1,2}$, K. Bednis ${ }^{1}$, C. Hawke ${ }^{1,2}$, A. Bidos ${ }^{4}$, J. Bloom ${ }^{1,2}$, Y. R. Rampersaud ${ }^{1,2,3}$, N. Haroon ${ }^{1,2,3}$, R. Inman ${ }^{1,2,3}$. 'Toronto Western Hospital; ${ }^{2}$ University of Toronto; ${ }^{3}$ Krembil Research Institute; ${ }^{4}$ University Health Network, Toronto, Canada

Background: People with axial spondyloarthritis (SpA) wait an average of 9 years between onset of back pain and time to diagnosis by a rheumatologist (Feldkeller 2000). During this time, patients often experience significant pain and dysfunction, while waiting for appropriate diagnosis and intervention. Understanding patients' perspectives of this diagnostic process is essential in order to optimize early detection and promote appropriate management for axial SpA.

Objectives: The purpose of this study was to understand patients' perspectives of referral and screening practices for axial SpA from onset of back pain to diagnosis by a rheumatologist.

Methods: Semi-structured key informant interviews were conducted with patients diagnosed with axial SpA, based on ASAS criteria, attending a tertiary academic spondylitis clinic. Interviews addressed patients' experiences with screening and referral practices for adults with chronic back pain and suspected axial SpA from symptom onset to diagnosis. All interviews were recorded, transcribed verbatim and evaluated using a compare and contrast analysis by coding groups of words that addressed the research objectives. Two members of the research team undertook this exercise independently and then met to reconcile emergent overarching categories and their respective themes. NVIVO V9 was used to assist with organization of codes.

Results: A total of 10 patient interviews were conducted. $90 \%$ of participants were male, mean age 42.8 years $( \pm 12.6)$. The mean duration of back pain prior to diagnosis of axial SpA was 8.9 years $( \pm 6.0)$. The majority of patients $(90 \%)$ had post-secondary education. Three overarching categories were identified regarding patients' experiences with screening and referral practices for axial SpA from symptom onset to diagnosis and included: 1) "system factors"; 2) "healthcare provider factors" and 3) "patient factors". Themes related to "system factors" included timely and appropriate access to care. Perceived lack of clinical skills and healthcare provider interpersonal skills were allocated to the category of "healthcare provider factors". Themes identified under the category of "patient-related factors" included: coping with uncertainty; the role of health literacy; the notion of hope, and the belief of stoicism.

Conclusions: The results of this study indicate that care provided by knowledgeable, caring, empathetic and receptive healthcare providers is critical to patients with axial SpA as they navigate the healthcare system from symptom onset to 